\title{
Early Alterations in Functional Connectivity and White Matter Structure in a Transgenic Mouse Model of Cerebral Amyloidosis
}

\author{
Joanes Grandjean, ${ }^{1,2}$ Aileen Schroeter, ${ }^{1}$ Pan He, ${ }^{3}$ Matteo Tanadini, ${ }^{4}$ Ruth Keist, ${ }^{5}$ Dimitrije Krstic,, 5 Uwe Konietzko, ${ }^{2,6}$ \\ Jan Klohs, ${ }^{1,2}$ Roger M. Nitsch, ${ }^{2,6}$ and Markus Rudin ${ }^{1,2,5}$ \\ ${ }^{1}$ Institute for Biomedical Engineering, and ${ }^{2}$ Center for Neuroscience Research, University and ETH Zurich, 8093 Zurich, Switzerland, ${ }^{3}$ Department of \\ Information Technology and Electrical Engineering, and ${ }^{4}$ Seminar for Statistics, ETH Zurich, 8092 Zurich, Switzerland, and ${ }^{5}$ Institute of Pharmacology and \\ Toxicology and ${ }^{6}$ Division of Psychiatry Research, University of Zurich, 8008 Zurich, Switzerland
}

Impairment of brain functional connectivity (FC) is thought to be an early event occurring in diseases with cerebral amyloidosis, such as Alzheimer's disease. Regions sustaining altered functional networks have been shown to colocalize with regions marked with amyloid plaques burden suggesting a strong link between FC and amyloidosis. Whether the decline in FC precedes amyloid plaque deposition or is a consequence thereof is currently unknown. The sequence of events during early stages of the disease is difficult to capture in humans due to the difficulties in providing an early diagnosis and also in view of the heterogeneity among patients. Transgenic mouse lines overexpressing amyloid precursor proteins develop cerebral amyloidosis and constitute an attractive model system for studying the relationship between plaque and functional changes. In this study, $\operatorname{ArcA} \beta$ transgenic and wild-type mice were imaged using resting-state fMRI methods across their life-span in a cross-sectional design to analyze changes in FC in relation to the pathology. Transgenic mice show compromised development of FC during the first months of postnatal life compared with wild-type animals, resulting in functional impairments that affect in particular the sensory-motor cortex already in preplaque stage. These functional alterations were accompanied by structural changes as reflected by reduced fractional anisotropy values, as derived from diffusion tensor imaging. Our results suggest cerebral amyloidosis in mice is preceded by impairment of neuronal networks and white matter structures. FC analysis in mice is an attractive tool for studying the implications of impaired neuronal networks in models of cerebral amyloid pathology.

Key words: $\operatorname{ArcA} \beta$; diffusion tensor imaging; fMRI; functional connectivity; mouse; resting state

\section{Introduction}

The occurrence of amyloid plaques in brain parenchyma and around the cerebral vessels constitutes a hallmark of Alzheimer's disease (AD; Iwatsubo et al., 1994). Cerebral amyloidosis involves the aggregation of $A \beta$ peptides, a cleavage product of the amyloid precursor protein (APP). In $\mathrm{AD}$, plaque deposits, fibrils, and oligomers of $\mathrm{A} \beta$ are considered essential mediators in the pathophysiological cascade leading to cognitive decline (Mucke and Selkoe, 2012). A $\beta$ peptides in various forms have been linked to alterations in cerebral calcium homeostasis (Kuchibhotla et al., 2008), axonal guidance (Cao et al., 2012), axonal transport, and/or synaptic signaling (Knobloch et al., 2007a), processes that ultimately might translate into impaired neural function.

\footnotetext{
Received Nov. 8, 2013; revised Aug. 13, 2014; accepted Aug. 16, 2014.

Author contributions: J.G. and M.R. designed research; J.G. and A.S. performed research; R.K., D.K., U.K., J.K., and R.M.N. contributed unpublished reagents/analytic tools; J.G., P.H., and M.T. analyzed data; J.G. and M.R. wrote the paper.

This study was supported by the Swiss National Science Foundation (SNF 310030-141202, SNF 310030-126029). The authors declare no competing financial interests.

Correspondence should be addressed to Markus Rudin, Institute for Biomedical Engineering, Wolfgang-PauliStreet 27, 8093 Zurich, Switzerland. E-mail: rudin@biomed.ee.ethz.ch.

DOI:10.1523/JNEUROSCI.4762-13.2014

Copyright $\odot 2014$ the authors $\quad 0270-6474 / 14 / 3413780-10 \$ 15.00 / 0$
}

Marked functional impairments have been observed in patients with AD using fMRI (Greicius et al., 2004; Johnson et al., 2012). In particular, resting-state fMRI (rs-fMRI) has been extensively used to investigate functional connectivity (FC) as derived from the apparent synchronicity of the fMRI signal of distinct brain regions. Human brain appears organized into 10-15 networks (Damoiseaux et al., 2006), among which, the default mode network (DMN) has gained attention in AD due to its colocalization with amyloid plaques (Greicius et al., 2003; Buckner et al., 2005). Additionally, DMN connectivity was reported affected in subjects at risk of developing $\mathrm{AD}$ including patients with mild cognitive impairment (Rombouts et al., 2005; Sorg et al., 2007), in cognitively healthy elders with amyloid deposits (Hedden et al., 2009; Sperling et al., 2009; Sheline et al., 2010b), and in midlife carriers of APO $\varepsilon 4$ risk allele (Sheline et al., 2010a; Canuet et al., 2012). Elucidating the relationship between plaque deposition and functional network change in a temporal and spatially resolved manner is essential for understanding the pathophysiological cascade and may provide an early diagnostic tool. However, the heterogeneity among AD patients combined with poor method reproducibility at the individual level, the latency of disease onset and difficulties to accurately perform early diagnostics in patients have rendered such studies in humans difficult. 
Table 1. Number of animals used in the study per age group and genotype, mean tSNR in the S1 sensory cortex, and mean animal motion during fMRI acquisition

\begin{tabular}{|c|c|c|c|c|c|c|}
\hline Group & Genotype & Age (month \pm SD) & $N$ (female/male) & tSNR S1 ( \pm SD) & Maximum motion $(\mu \mathrm{m} \pm \mathrm{SD})$ & Variance motion $\left(\mu \mathrm{m}^{2} \pm \mathrm{SD}\right)$ \\
\hline$A$ & WT & $1.56(0.11)$ & $10(5 / 5)$ & $164.2(20.4)$ & 41 (17) & $0.16(0.17)$ \\
\hline$A$ & TG & $1.5(0.08)$ & $11(4 / 7)$ & $162.1(34.8)$ & $39(24)$ & $0.14(0.13)$ \\
\hline$A$ & WT & $2.63(0.13)$ & $10(5 / 5)$ & $180.8(14.2)$ & 40 (14) & $0.17(0.11)$ \\
\hline$A$ & TG & $2.67(0.11)$ & $11(4 / 7)$ & $184.1(12.4)$ & $44(25)$ & $0.22(0.29)$ \\
\hline$B$ & WT & $5.48(0.57)$ & $8(6 / 2)$ & $113.4(16.5)$ & $39(33)$ & $0.32(0.22)$ \\
\hline$B$ & $\mathrm{TG}$ & $5.53(0.47)$ & $8(6 / 2)$ & $113.2(15)$ & $47(44)$ & $0.31(0.28)$ \\
\hline$C$ & WT & $8.58(0.15)$ & $9(6 / 3)$ & $104.7(16.5)$ & $44(21)$ & $0.38(0.53)$ \\
\hline$C$ & TG & $8.58(0.15)$ & $9(6 / 3)$ & $117.9(15.5)$ & $30(14)$ & $0.31(0.60)$ \\
\hline$C$ & WT & $11.22(0.02)$ & $9(6 / 3)$ & $139(17.8)$ & $35(24)$ & $0.18(0.21)$ \\
\hline$C$ & TG & $11.21(0.03)$ & $9(6 / 3)$ & $154.5(22.1)$ & $31(20)$ & $0.59(0.71)$ \\
\hline$D$ & WT & $19.15(0.14)$ & $9(7 / 2)$ & $102.6(24.5)$ & $45(32)$ & $0.51(0.75)$ \\
\hline$D$ & TG & $19.18(0.14)$ & $10(5 / 5)$ & $101.8(21.8)$ & $49(29)$ & $0.59(0.71)$ \\
\hline$D$ & WT & $21.83(0.01)$ & $7(5 / 2)$ & $146.4(26.3)$ & $22(12)$ & $0.07(0.06)$ \\
\hline$D$ & TG & $21.83(0.01)$ & $10(5 / 5)$ & $173.6(38)$ & $37(27)$ & $0.23(0.41)$ \\
\hline
\end{tabular}

WT, Wild-type; TG, transgenic.

Animal models of amyloid pathology offer an experimental platform to studying $\mathrm{AD}$ (Gordon et al., 2002). Although the molecular processes underlying amyloid pathology in animals have been examined extensively, studies addressing its implication on brain FC are lacking as fMRI in mice is challenging. We have assessed the FC in mice across their lifespan, from 1 to 21 months, in a cross-sectional design using rs-fMRI. The ArcA $\beta$ transgenic mouse model of cerebral amyloidosis has been used, which overexpresses the human APP protein with the Swedish and Arctic mutations. The mice show reduced synaptic plasticity (Knobloch et al., 2007a), and amyloid pathology affecting both the brain parenchyma and vasculature by 6 months of age (Knobloch et al., 2007b; Merlini et al., 2011). To obtain a structural correlate for FC changes, we have complemented fMRI measurements with diffusion tensor imaging. Combining structural and functional connectivity data in a temporally resolved manner provides valuable insight into the mechanisms underlying the alterations observed in mouse models of amyloidosis.

\section{Materials and Methods}

Animal preparation. All animal experiments in this study have been performed in adherence to the Swiss law of Animal Protection and were approve by the Zurich cantonal veterinary office. A total of 38 (17 male, 21 female) transgenic ArcA $\beta$ mice and 36 ( 12 male and 24 female) wildtype littermates aged between 1 and 21 months were used in this study in four different age groups (A-D), imaged at 1 and 2 months (Group A), at 5 months (Group B), at 8 and 11 months (Group C), and at 19 and 21 months (Group D). The groups and corresponding group sizes are summarized in Table 1 . Animals were housed in standard mouse caging, with $12 \mathrm{~h} \mathrm{light/dark}$ cycles with food and water provided ad libitum. Mice were anesthetized with isoflurane (Abbott) in 1:4 oxygen to air mix at 3\% for induction and $1.4 \%$ during measurements administered via a facemask. Animals were placed on a mouse support with ear bars placed to reduce animal motion during the experiments. The body temperature was monitored with a rectal thermometer and kept at $36.5^{\circ} \mathrm{C} \pm 0.5^{\circ} \mathrm{C}$ with an adjustable warm water bath contained in the support. Measurement including mouse preparation typically lasted for $45 \mathrm{~min}$. Animals were measured a second time in a week interval to evaluate reproducibility. Animals at 11 and 21 months were killed for histology.

MRI. A BioSpec 94/30 animal MRI system (Bruker BioSpin GmbH) equipped with a $9.4 \mathrm{~T}$ magnet with a horizontal bore of $30 \mathrm{~cm}$ diameter, a BGA12S gradient system capable of a maximum gradient strength of $400 \mathrm{mT} / \mathrm{m}$ with a $80 \mu$ s rise time, a $2 \times 2$ cryogenic phased-array receive coil, and a linear volume resonator coil for excitation have been used. Anatomical images have been recorded using a multislice rapid acquisition with relaxation enhancement sequence with repetition time (TR) = $2500 \mathrm{~ms}$, echo time $(\mathrm{TE})=11 \mathrm{~ms}$, effective echo time $($ TEeff $)=33 \mathrm{~ms}$, pulse angle $(\mathrm{PA})=90^{\circ}$, number of averages $(\mathrm{NA})=1$, matrix dimension
$(\mathrm{MD})=180 \times 180$, pixel dimensions $(\mathrm{V})=111 \times 97 \mu \mathrm{m}^{2}$, slice thickness $(\mathrm{STH})=500 \mu \mathrm{m}$, interslice distance $(\mathrm{ISD})=200 \mu \mathrm{m}$, and number of slices $(\mathrm{NSl})=12$. For fMRI studies gradient-echo echo-planar imaging (EPI) was with $\mathrm{TR}=1500 \mathrm{~ms}, \mathrm{TE}=9.3 \mathrm{~ms}, \mathrm{PA}=50^{\circ}$, number of repetition $(\mathrm{NR})=500, \mathrm{NA}=1, \mathrm{MD}=90 \times 70, \mathrm{~V}=250 \times 220 \mu \mathrm{m}^{2}$, $\mathrm{STH}=500 \mu \mathrm{m}, \mathrm{ISD}=200 \mu \mathrm{m}, \mathrm{NSl}=12$. Diffusion tensor imaging was performed using a multisegment DTI-EPI sequence, with TR $=3000 \mathrm{~ms}$, $\mathrm{TE}=25 \mathrm{~ms}, \mathrm{PA}=90^{\circ}$, number of segments $=4, \mathrm{NA}=1, \mathrm{MD}=128 \times$ $128, \mathrm{~V}=160 \times 130 \mu \mathrm{m}^{2}, \mathrm{STH}=500 \mu \mathrm{m}, \mathrm{ISD}=200 \mu \mathrm{m}, \mathrm{NSl}=12, b$ value of $690 \mathrm{~s} / \mathrm{mm}^{2}$, and 36 diffusion encoding directions. Shimming was performed using MAPSHIM protocol.

Images processing. Images were preprocessed in SPM05 (FIL Group) for MATLAB (MathWorks). Functional MR images were realigned, corrected for slice timing and a nonlinear transformation was applied to match to an in-house EPI template (Fig. 1a,b). The template has been obtained as the mean of 10 coregistered EPI datasets that have been recorded in a separate experiment. To obtain enforce bilateral symmetry, the original and mirrored EPI data have been averaged. Motion correction was performed using the tools provided by SPM. Temporal variance was computed voxelwise and averaged between all scans to obtain maps revealing clusters of high variances in regions associated with large vessels. The signal traces in these clusters were used a regressors in the voxelwise analysis to account for contributions arising from the vasculature (Fig. 1c). Initially, we also evaluated for a potential influence from respiration using RETROICOR (Glover et al., 2000), yet observed that it had negligible effect on the results. Hence, this contribution was not furthermore considered. The resulting time series for each voxel were then bandpass filtered using a range between 0.01 and $0.15 \mathrm{~Hz}$ (Rest toolbox, State Key Laboratory of Cognitive Neuroscience and Learning) for MATLAB. Mean time series were extracted from the regressed images using an in-house atlas template based on the functional organization of the mouse brain with 24 different ROIs (Fig. 1d). Functional connectivity was measured as the Pearson correlation coefficient between mean time series from each brain region pairs, corrected with Fisher $z$-transformation for bounded values.

Fractional anisotropy (FA) was computed from diffusion tensor images using Paravision 5 (Bruker BioSpin $\mathrm{GmbH}$ ). Images were converted to Analyze7.5 format and normalized to a reference space using $b_{0}$ images with SPM05. Fractional anisotropy values were extracted for selected regions-of-interest (ROIs).

All unprocessed anatomical, diffusion tensor, and functional images were made freely available at central.XNAT.org in Analyze7.5 format (Project ID: fMRI_AD_mouse).

Histology. Animals were deeply anesthetized with ketamine/xylazine, and transcardially perfused with cold PBS followed by $4 \%$ paraformaldehyde. Brains were extracted and put in paraformaldehyde overnight. Brains were transferred in succession in 10,20, and $30 \%$ sucrose solution, before being frozen at $-80^{\circ} \mathrm{C}$. Randomly sampled serial sections (cut at $40 \mu \mathrm{m}$ ) were collected and stored at $-20^{\circ} \mathrm{C}$ in cryoprotectant solution 
a

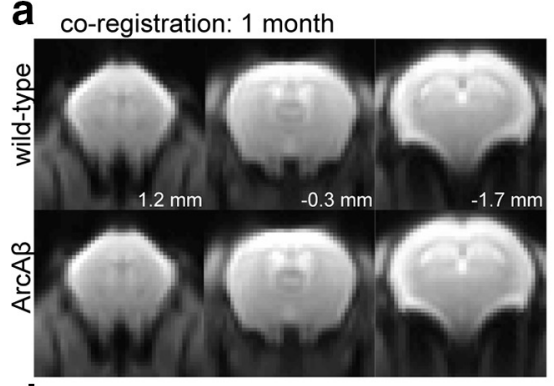

d Atlas

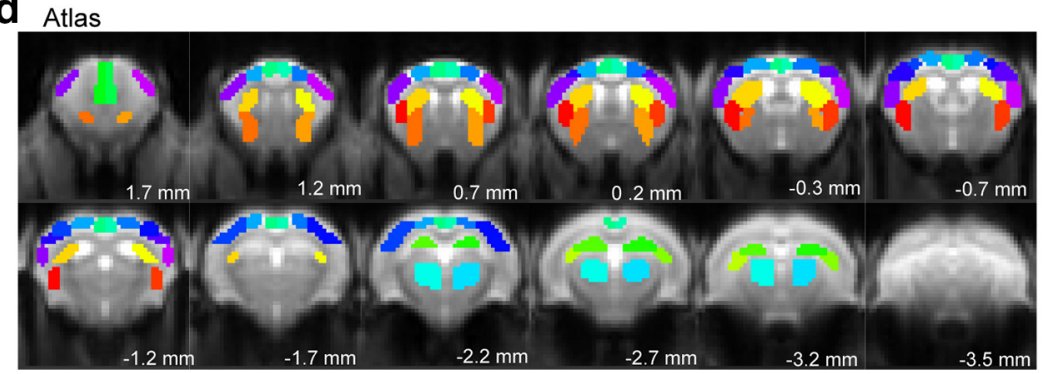

b

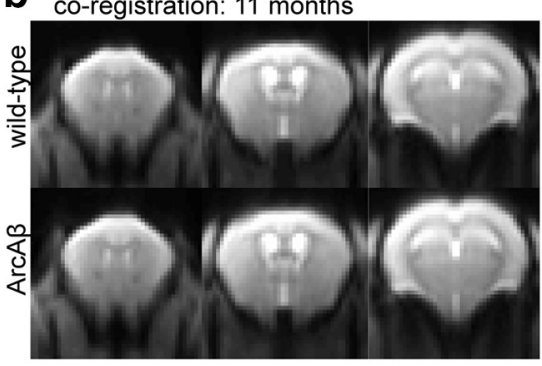

C nuisance regression

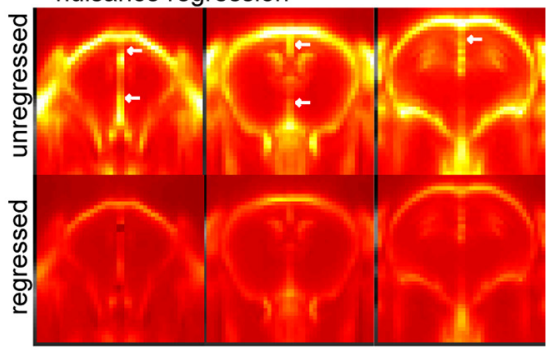

Key:

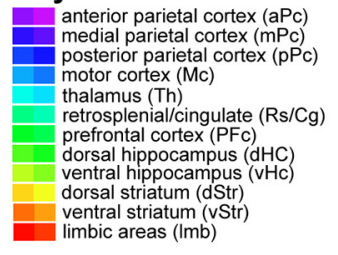

Figure 1. EPI images were normalized to an in-house template using nonlinear coregistration. The mean of the coregistered images are shown for 1-month-old (a) and 11-months-old (b) for both wild-type and transgenic mice, and illustrate the performance of the coregistration procedure. No visible difference appears between the groups suggesting the validity of the linear and nonlinear transformation applied. Temporal variance maps revealed clusters with high variance in the brain boundaries and in areas colocalizing with major blood vessels (c, white arrows). Voxelwise regression was performed with the signal extracted from these regions, leading to reduced variance in these regions. A color-coded atlas template was used for network analysis showing 24 ROIs based on the functional organization of the mouse brain $(\boldsymbol{d})$. The distance of the respective section from bregma in millimeters is indicated.

(50 mmol/L sodium phosphate buffer, $\mathrm{pH} 7.4$, containing $15 \%$ glucose and $30 \%$ ethylene glycol; Sigma-Aldrich). The free-floating sections were treated for $10 \mathrm{~min}$ with pepsin (Dako) $0.15 \mathrm{mg} / \mathrm{ml}$ in $0.2 \mathrm{~N} \mathrm{HCl}$ at $37^{\circ} \mathrm{C}$. After three washes in PBS, the pepsin-treated brain sections were then incubated overnight at $4^{\circ} \mathrm{C}$ in the primary antibody solution (mouse monoclonal amyloid- $\beta_{1-16}$, clone $6 \mathrm{E} 10$, diluted $1: 1000$, Covance) diluted in PBS containing 2\% normal goat serum and $0.2 \%$ Triton X-100. After three washes in PBS, tissue sections were incubated for $30 \mathrm{~min}$ at RT in biotinylated secondary antibody (diluted 1:500; Jackson ImmunoResearch Laboratories). A commercial kit (Vectastain Kit; Vector Laboratories) was then used with 3,3-diaminobenzidine (Sigma-Aldrich), and sections were stained for 5-10 min. After three washes in PBS, sections were mounted onto gelatinized glass slides and air-dried overnight. The sections were then dehydrated through ethanol, cleared in xylene, mounted with resinous mounting medium (EukittTM, Sigma-Aldrich), and coverslipped. ROI analysis was performed in ImageJ (NIH) to estimate the fractional surface occupied by amyloid plaques by delineating the cortical regions according to the atlas used for the FC analysis.

Statistics. Statistical analysis was performed using the statistical software R 2.13.0 (The R Foundation for Statistical Computing). A linear mixed model analysis was performed with gender, age, genotype, and their twofold interactions as fixed effects using lme4 package. We applied the Fisher's $z$-transformation to the response variable. The effects of each interaction and factor were tested with Likelihood Ratio Tests. Residual analysis of the mixed models was performed on randomly selected samples $(n=30)$ with QQ-plots to inspect normal distribution, TukeyAnscombe plots for the homogeneity of the variance and skewness, and scale location plots for homoscedasticity (i.e., the homogeneity of residual variance). The assumption of normally distributed residuals was considered plausible in all tested fractional anisotropy samples and in all of the randomly tested functional connectivity pairs describing cortical interactions. In a post hoc analysis, the changes of correlation per time were extracted for the following intervals: $1-5$ and 5-19 months, and contrasts were used in the mixed-model analysis to test differences in the response variable between in wild-type and transgenic mice at these intervals. Multiple comparison was corrected with false discovery rate (FDR) (Benjamini and Hochberg, 1995), with $q=0.05$ for network comparison, and $q=0.15$ for voxelwise analysis. Voxelwise maps were further filtered for statistically significant clusters of 15 voxels or more. The null hypothesis, i.e., the absence of effect for a given factor or interaction, was rejected according to the FDR threshold, and is denoted in the text as factor effect for simplicity (e.g., genotype effect, genotype $\times$ age interaction effect, etc.). Values in plots and images are shown as mean value per group and error bars represent $\pm 1 \mathrm{SD}, p$ values are shown as $\log _{10}$ ( $p$ value) to account for the large range of values.

\section{Results}

\section{Group description}

During the study, a small portion of animals developed comorbidities or abnormal structures observed with $\mathrm{T}_{2}$ anatomical images: two animals with abnormal ventricles (1-month-old transgenic, 19month-old transgenic), one animal with focal hypointensity in the thalamus (1-month-old transgenic). In addition, two wild-type animals had to be killed between measurements at 19 and 21 months due to age-related events. All animals measured were included in the analysis.

\section{Preprocessing}

EPI image deformation induced by the magnetic field inhomogeneity was minimal in most scans and was accounted for by the nonlinear transformation during the coregistration. There was no apparent difference related to coregistration in the mean images in the individual groups as illustrated with 1- and 11-monthold animals (Fig. 1a,b). Temporal variance maps revealed clusters of high variance in areas colocalizing with major blood vessels (shown with white arrows) and at the brain boundaries (Fig. 1c). The signal traces were then extracted from these regions and regressed from the time series for every voxel (to account for vascular contributions) along with the motion parameters, which led to an effective reduction in variance in region as indicated by the variance analysis (Fig. 1c).

\section{Development of FC during early months of life}

In wild-type mice, the correlation coefficient between rs-fMRI time series for ROIs located within the parietal and motor corti- 


\section{a 1 month}

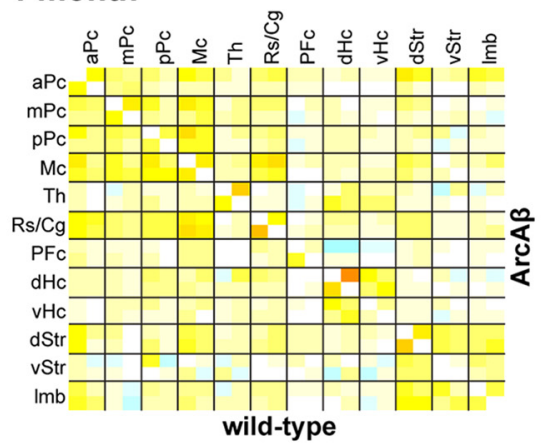

\section{d 8 months}

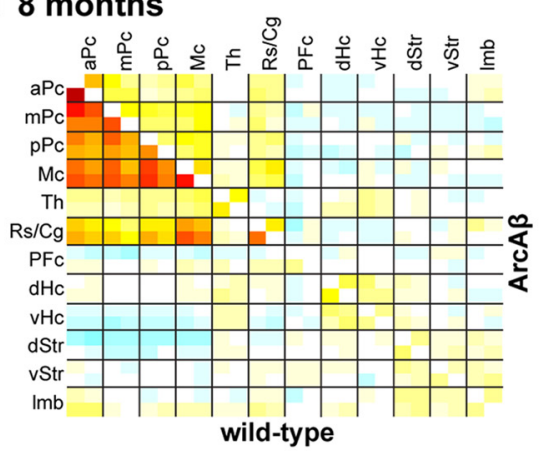

\section{g 21 months}

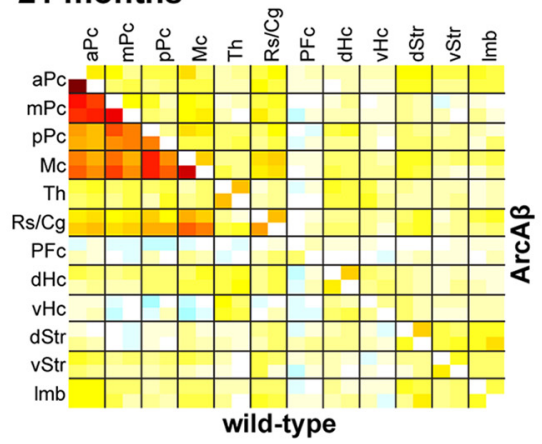

b 2 months

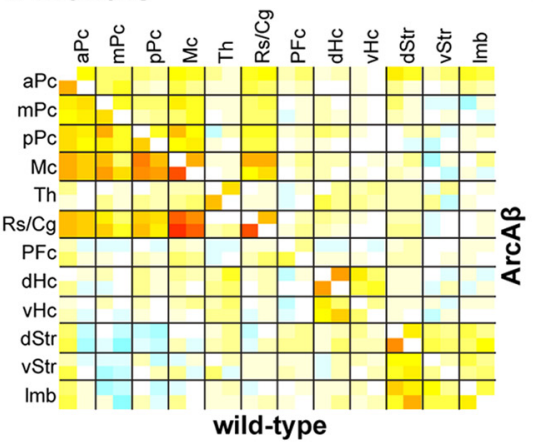

e 11 months

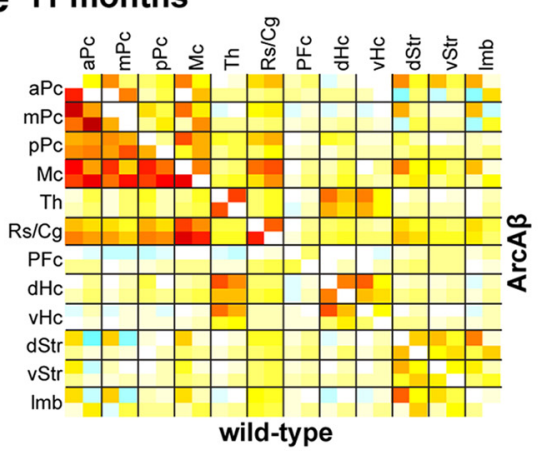

h statistics

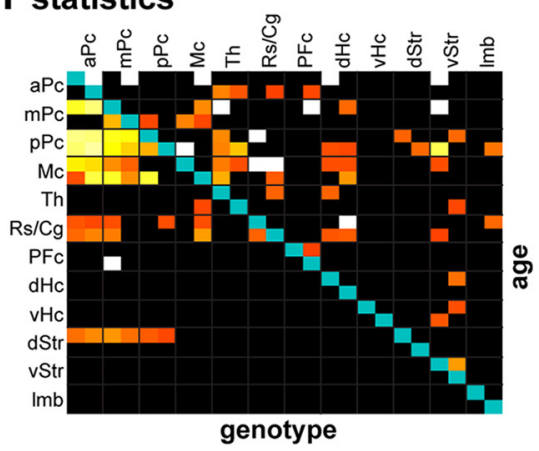

\section{5 months}

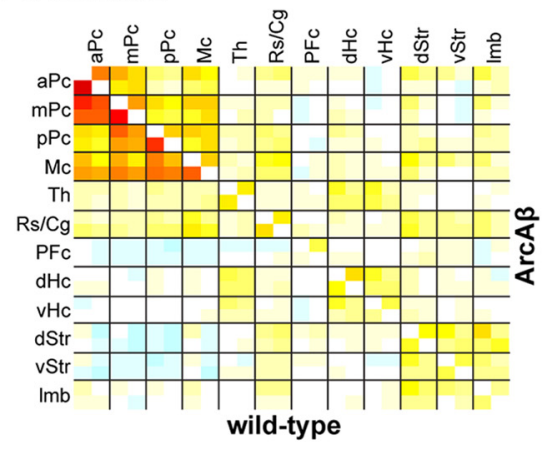

f 19 months

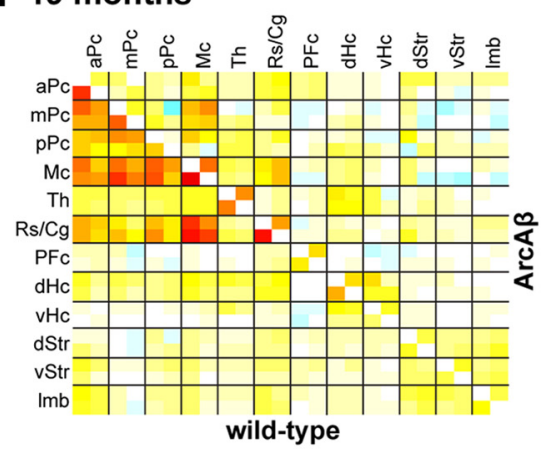

Figure 2. Network analysis of cortical regions showing cross-correlations in wild-type (bottom, left of FC matrix) and ArcA $\beta$ mice (top, right of FC matrix), at 1 ( $\boldsymbol{a}), 2(\boldsymbol{b}), 5(\boldsymbol{c}), 8(\boldsymbol{d}), 11(\boldsymbol{e}), 19(\boldsymbol{f})$, and $21(\boldsymbol{g})$ months of age. Color-coded values represent the mean Pearson correlation coefficients per group corrected with Fisher z-transformation. The two elements for each cortical area correspond to ROls in left and right hemisphere, respectively. Strongest correlations in the wild-type groups are observed between left and right parietal (aPc, $\mathrm{mPc}$, pPc), motor (Mc), and retrosplenial/cingulate cortex (Rs/Cg). (h) Pairwise mixed-model analysis showing the genotype and age effects below FDR correction threshold. Color-coded values represent the log $p$ value for each effect ranging from 0 to -15 , corrected with FDR.

ces developed from values in the range of $z=0.15-0.32$ at 1 month to values of $z=0.4-0.89$ measured at 5 months of age (Figs. 2, $3 a-c$ ). Similarly, although less pronounced, changes have been found in cross-correlation between bilateral retrosplenial/ cingulate cortex and the retrosplenial/cingulate with the parietal cortices (Figs. 2, 3d). The hippocampus (Figs. 2, 3e) displayed weak correlations with coefficients $z \leq 0.5$ bilaterally, and $z \leq 0.1$ with other regions. Correlation did not exceed $z=0.3$ between the dorsal and ventral striatum and the cortical regions (Fig. 2).

\section{ArcA $\beta$ mice display impaired age related FC development}

Correlation coefficients observed in 1-month-old $\operatorname{ArcA} \beta$ mice were similar to the age-matched wild-type animals across all regions analyzed, the mice developed FC difference with respect to wild-type between month 1 and 5 for the cortical ROIs (Figs. $2 a-c, 3 a-c)$. Statistical analysis of the correlation matrices (Fig. $2 h$ ) revealed strong genotype effect for correlations among left and right medial and posterior parietal cortices, as well as motor cortices (Fig. $3 b, c$; posterior parietal cortices $p=3.3 \times 10^{-9}$, motor cortices $\left.p=5.1 \times 10^{-3}\right)$. There was no genotype $\times$ age interaction below FDR threshold. Correlations from the parietal cortices to the motor cortex showed an age effect (Fig. $2 h$ ). None of the correlation pairs, however, showed a gender effect or gender interaction effects below FDR threshold.

The rate of change of the correlation value per month ( $\Delta$ Correlation/month) was evaluated using linear regression for the 1-5 month (Fig. 4a) and 5-19 month intervals (Fig. 4b), respectively, and displayed reduced rates for several cortical ROIs in $\operatorname{ArcA} \beta$ compared with wild-type mice during the 1-5 month period, but not during the 5-19 month interval (Fig. 4c). For example, for the 1-5 month period, the $\Delta$ Correlation/month rate in the medial parietal cortex were $2.7 \times 10^{-3}$ month $^{-1}$ in $\operatorname{ArcA} \beta$ against $6.5 \times 10^{-3}$ month $^{-1}$ in wild-type mice (Fig. $4 a, c$; difference: $3.8 \times 10^{-3}$ month $\left.^{-1}\right)$, whereas for the interval 5-19 
months the corresponding values were $1.5 \times 10^{-4}$ month $^{-1}$ for $\operatorname{ArcA} \beta$ and $-1.9 \times 10^{-4}$ month $^{-1}$ for wild-type mice, respectively (Fig. 4b,c; difference: $-3.4 \times 10^{-4}$ month $^{-1}$ ). The genotype contrast for the 1-5 month and 5-19 month interval indicated overall statistical significant differences across cortical ROIs between wild-type and $\operatorname{ArcA} \beta$ mice during the 5-19 months interval, but only marginal difference during the 1-5 months interval (Fig. 4d).

Seed-based analysis of the left anterior parietal cortex (Fig. 5) illustrates the change of cross-correlation from 1 month to 5,8 , and 21 months of age. In both $\operatorname{ArcA} \beta$ and wild-type mice, a seed ROI located within the somatosensory S1 cortex showed weak diffuse correlation with the adjacent cortex, and little bilateral correlations at 1 month. In wild-type animals, correlation to the contralateral parietal cortices increased by 5 months of age from $z=0.25$ to 0.6 consistent with the values from the network analysis discussed above. In ArcA $\beta$ mice, FC to the contralateral parietal cortex remained below the threshold value of $z=0.1$ also at 5 , 8 , and 21 months of age.

\section{Associated changes in fractional anisotropy}

A genotype effect in FA changes was found for the minor forceps, the anterior part of the external capsule, and the anterior internal capsule (Fig. 6b). Age effect on FA values was widespread in the white and gray matter (data not shown), while a gender effect was identified for the anterior internal capsule (Fig. $6 c$ ). No factor interaction (e.g., genotype $\times$ age) effect was observed below the FDR threshold. Slope analysis for the 1-5 month interval indicate that fibers highlighted by the statistical analysis presented greater rate of FA change per month $(\Delta \mathrm{FA} / \mathrm{month})$ in wild-type mice compared with transgenic animals. ROI analysis illustrates the difference in FA in the anterior external capsule in both wild-type and transgenic mice (Fig. $6 f$; genotype effect: $p=1.6 \times 10^{-3}$, age effect: $p=1.7 \times 10^{-7}$ ), but not in the posterior external capsule (Fig. $6 g$ ).

\section{Amyloid plaque deposition starts in the early life stage}

Although only anecdotal parenchymal plaques have been detected in brains of 5 months old $\operatorname{ArcA} \beta$ mice, amyloid pathology was densely present in the cortex and hippocampus in 11- and 21-month-old animals (Fig. 7a). Amyloid plaques occupied between 3.2 and $7.4 \%$ of the cortical surface in the different regions in 11 months $\operatorname{ArcA} \beta$ mice, and 11.9 and $18 \%$ at 21 months (Fig. $7 b$ ). There was however no correlation between the surfaces occupied by amyloid plaques and bilateral correlation between the corresponding areas (Fig. $7 c ; r=0.08$ ). A mixed model analysis was devised with fractional surface occupied by amyloid deposits as a response variable and $\mathrm{FC}$ values for the corresponding regions, age, and cortical region as explanatory effects. FC did not result in a significant effect, whereas there was a significant age and cortical region effect ( $p=6.5 \times 10^{-6}$ and $4.2 \times 10^{-3}$, respectively).
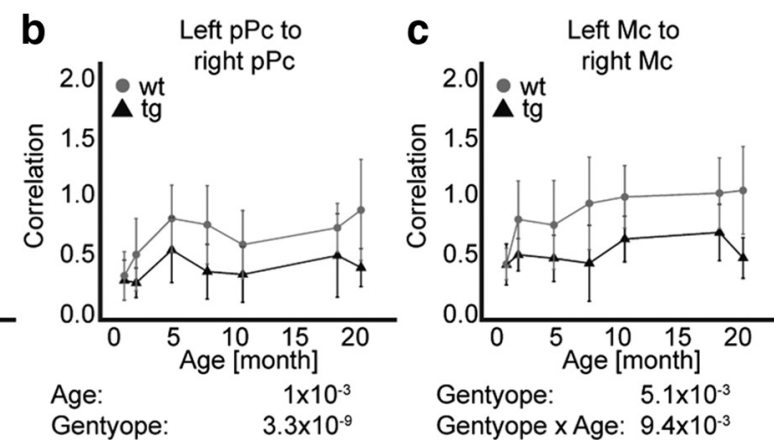

Gentyope x Age: $9.4 \times 10^{-3}$
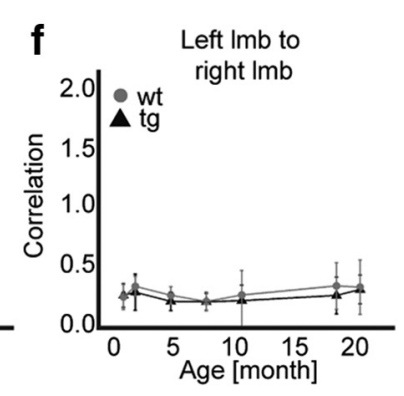

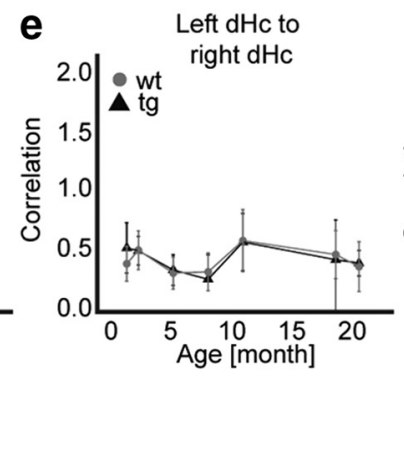

the mean value from transgenic Arc $A \beta$ mice; gray circles represent the mean value from wild-type controls. Young animals showed low correlation coefficient in cortical reftects. Genotype $\times$ raction effect was observed in the anterior and posterior parietal cortex bilateral correlation $\left(\boldsymbol{a}, p=2.5 \times 10^{-8} ; \boldsymbol{b}, p=5.5 \times\right.$ no genotype effect in the hippocampus $(\boldsymbol{e})$ or limbic regions $(\boldsymbol{f})$. Error bars represent \pm 1 SD.

\section{Potential confounds}

We have used isoflurane as an anesthetic, which has been shown to reveal predominantly cortical correlations, whereas medetomidine favored the detection of subcortical correlations. We have titrated isoflurane levels to achieve animal sedation, with lower doses resulting in excessive motion artifacts. Anesthesia resulted in breathing rates of $120 \pm 15$ breaths per min. There was no apparent difference in breathing rates between age groups or genotypes. Temporal signal-to-noise ratio (tSNR) in the somatosensory cortex was found to vary between functional imaging sessions (Table 1; Fig. 8c) with animals imaged at 2 and 21 months of age displaying the highest $\mathrm{tSNR}$ values. There was no differences in $\mathrm{tSNR}$ between wild-type and transgenic animals, or male and females at any time point. Motion derived from the realignment algorithm was used to assess maximum motion between the three translation vectors, as well as the variance of the motion vectors. No correlation between tSNR and motion could be observed. Finally, neither tSNR nor motion showed statistical significant effect in the linear mixed model analysis. Variance of the within-subject effect was lower than the residual variance by two orders of magnitude, which is corroborated with a relatively low correlation in test-retest analysis ranging between $r=0.4$ and $r=0.58$ across cortical pairwise correlations (Fig. $8 a$ ). For example medial parietal cortex bilateral correlation yielded a test-retest correlation of $r=0.48$ (Fig. $8 b$ ). In comparison, fractional anisotropy of the external capsule showed similar testretest values of $r=0.39$.

\section{Discussion}

Development of FC in the somatosensory and motor cortex, as derived from the temporal correlation of rs-fMRI signals, occurs 


\section{a rate 1 - 5 months}

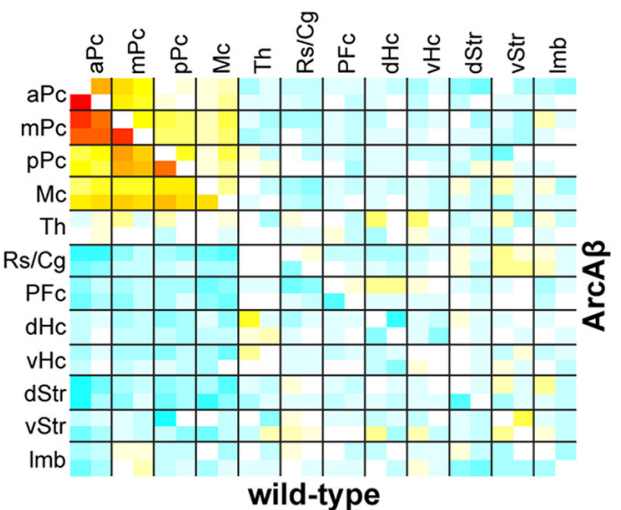

\section{C rate difference}

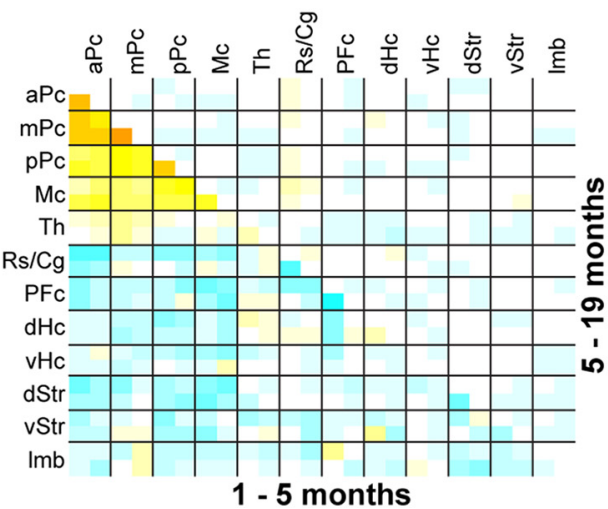

\section{b rate $5-19$ months}

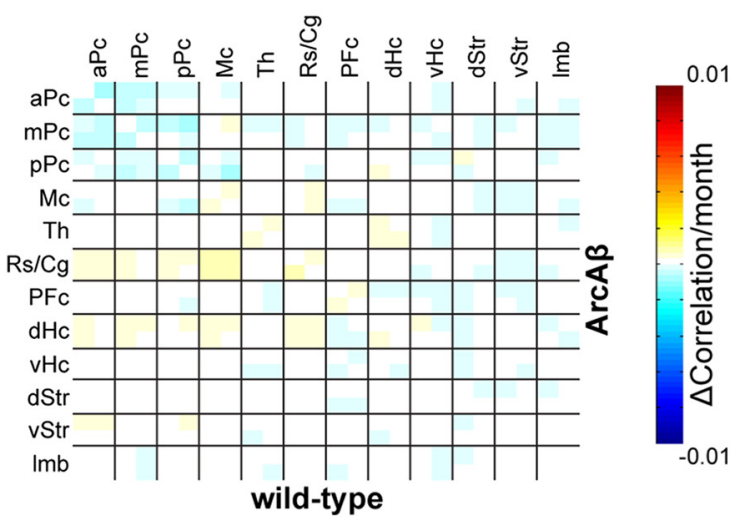

\section{d genotype contrast}

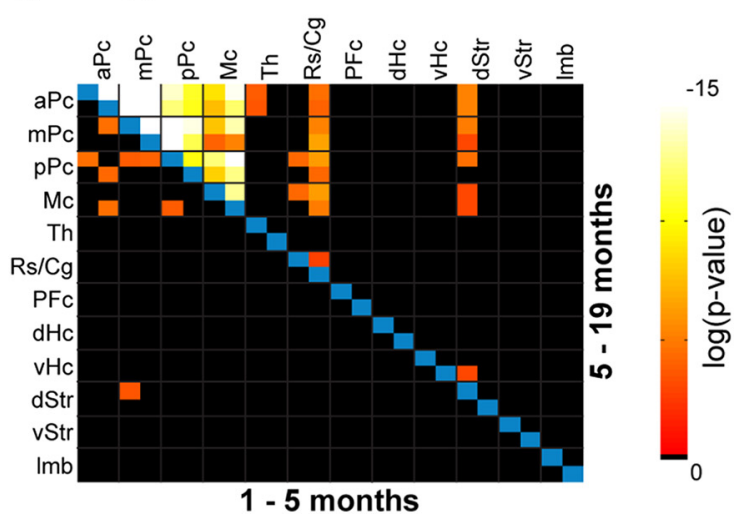

Figure 4. Correlation change in function of age in young adulthood ( $\boldsymbol{a}, 1-5$ months) and mid-life ( $\boldsymbol{b}, 5-19$ months) indicate lower rates in Arc $A \beta$ mice compared with wild-type during the early age in the cortical regions, with $\Delta$ correlation/month $=4.3 \times 10^{-3}$ to $1.3 \times 10^{-3}$ month $^{-1}$ in transgenic animals and $\Delta$ correlation/month $=7.6 \times 10^{-3}$ to $3.4 \times 10^{-3}$ month $^{-1}$ in

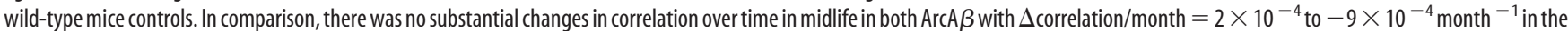
cortical areas, and wild-type mice with $\Delta$ correlation/month $=0$ to $-2 \times 10^{-4}$ month ${ }^{-1}$. The rate difference (c) reveals marked differences between ArcA $\beta$ and wild-type in $\Delta$ correlation/ month rates in the 1-5 months period in the anterior, medial and posterior parietal cortex, and marginal differences in rates during the 5-19 month interval. (d) Post hoc contrast analysis of differences between ArcA $\beta$ and wild-type between 1 and 5 months (bottom, left corner) and between 5 and 19 (top, right corner) reveals differences in correlation between the parietal cortices during the 5-19 month interval, but only marginal differences during the 1-5 month period.
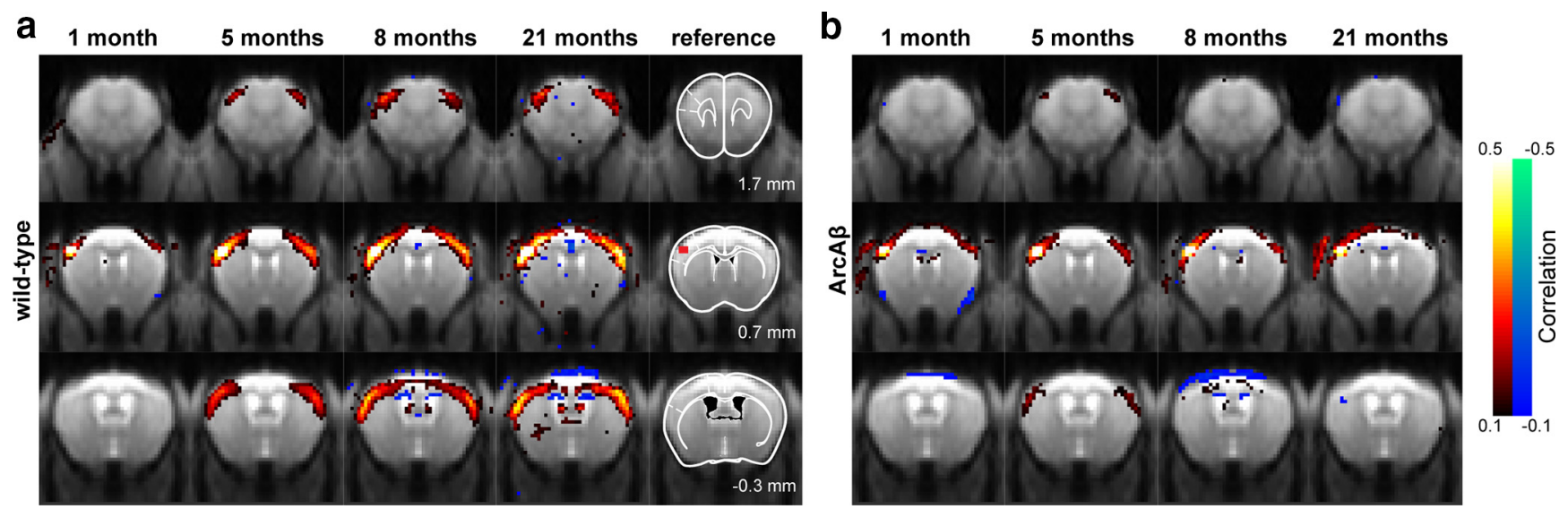

Figure 5. Seed-based analysis of the $S 1$ sensory cortex in wild-type $(\boldsymbol{a})$ and $\operatorname{ArcA} \beta$ mice $(\boldsymbol{b})$. At 1 month, both genotype groups show diffuse and weak cross-correlation between the seed region and the surrounding voxels in the cortex. Wild-type animals at 5, 8, and 21 months show correlations marking the delineation of the parietal cortex with respect to seed. In comparison, Arc $A \beta$ mice show weak contralateral correlations to the seed. Color-coded values represent the cross-correlation coefficient between the seed and the corresponding voxel ranging from $z= \pm 0.1 \mathrm{to} \pm 0.5$. The seed ROI is shown in red on the anatomical referenced. Values represent the distance from bregma in millimeters.

during the first months of life in wild-type mice and appears to be significantly impaired in age-matched $\operatorname{ArcA} \beta$ mice. These functional deficits are observed before and during the early plaque build-up stage, although there was only marginal decline in FC after 5 months of age during amyloid plaque buildup. Structural development, as reflected by FA measurements, also appears to be affected during the early months. The findings are in accordance with the previous description of amyloid pathology and 
$\mathbf{a}$

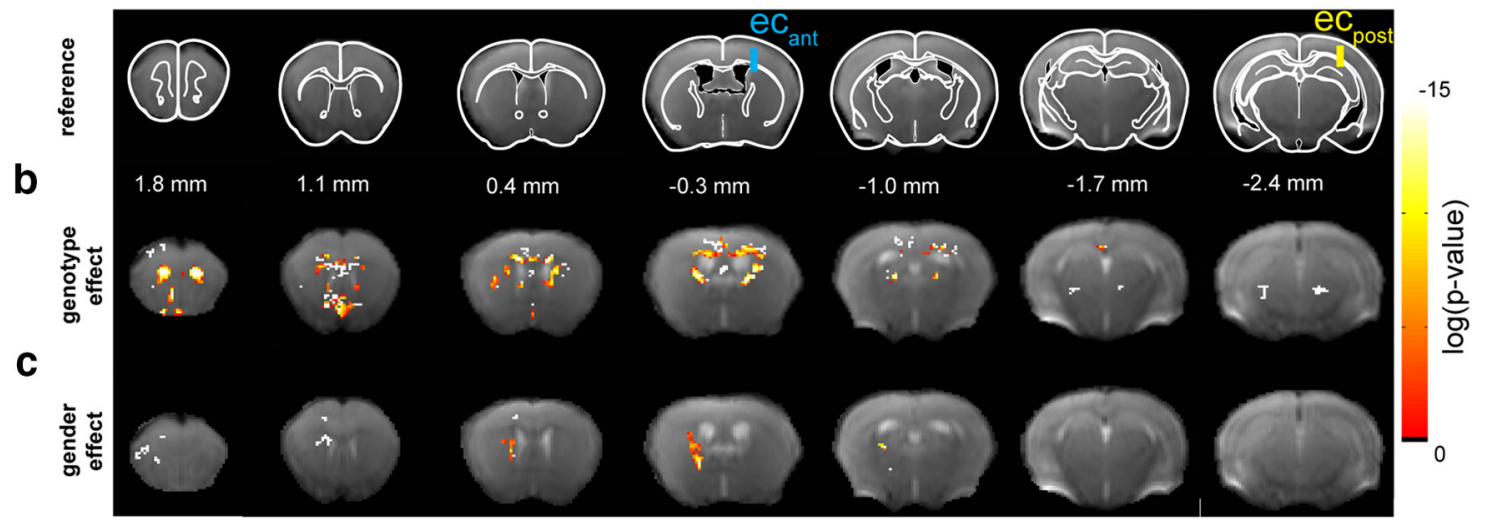

d

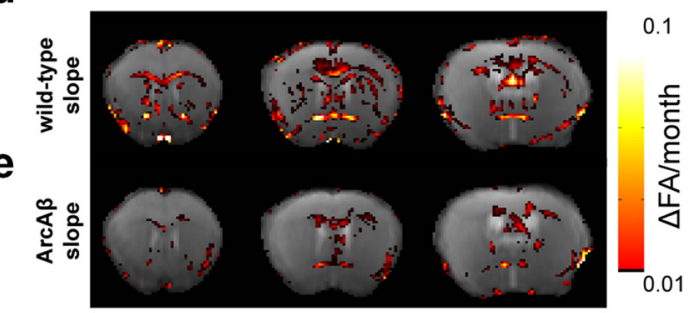

f

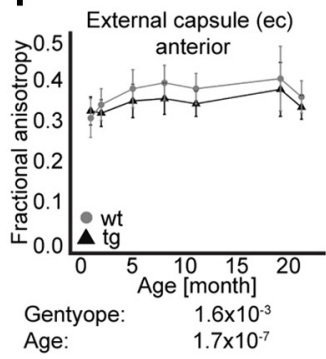

g

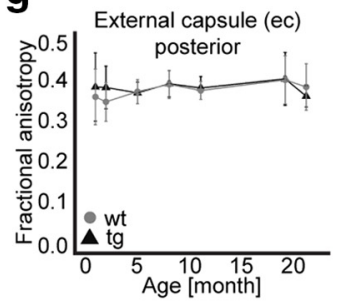

Figure 6. Reference image with anatomical overlay ( $\boldsymbol{a}$ ). Voxelwise analysis of $\mathrm{FA}$ in Arc $\beta$ and wild-type mice reveals a genotype effect in the corpus callosum, anterior external capsule, minor forceps and internal capsule $(\boldsymbol{b})$. A gender effect is found in the left internal capsule (c). Color-coded values represent the $\log p$ value corrected with false discovery rate and cluster size $\geq 15$. Rate of FA change per month ( $\triangle \mathrm{FA} / \mathrm{month}$ ) during the 1-5 month interval indicates higher rates in wild-type (d) compared with ArcA $\beta$ mice $(\boldsymbol{e})$ for fibers presenting a genotype effect in the voxelwise

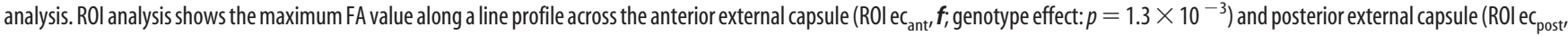
g) and illustrate the dynamics of FA changes between the genotypes over time. Black triangles represent the mean value from transgenic ArcA $\beta$ mice; gray circles represent the mean value from wild-type controls. Error bars represent \pm 1 SD. Statistics for each effect is shown under the plot for the significant effects.

cognitive deficits early in this mouse model (Knobloch et al., 2007b), and reduced synaptic long term potentiation observed at 3.5 months (Knobloch et al., 2007a).

The major finding of our study relates to the early and robust functional changes occurring in $\operatorname{Arc} A \beta$ transgenic mice, appearing before amyloid deposition as derived from histological analysis and reported earlier for this animal model (Knobloch et al., 2007b). The results compare well with growing evidence of early functional impairments in humans at risk of developing Alzheimer's disease, such as mid-life APO $\varepsilon 4$ carriers (Sheline et al., 2010a; Canuet et al., 2012) or asymptomatic elderly with amyloid deposition (Hedden et al., 2009; Sperling et al., 2009; Sheline et al., 2010b), and corroborate the reported absence of a correlation between amyloid plaques and functional connectivity in humans (Adriaanse et al., 2014). In a previous study of FC in APP/PS1 mouse model of AD, Bero et al. (2012) linked regions of high FC at 3 months in transgenic mice with regions at risk of developing amyloid plaques later in life, although the temporal dynamics of the change with respect to amyloid plaque appearance has not been demonstrated. Their results differ from ours as FC deficits in $\operatorname{ArcA} \beta$ mice appeared already robustly reduced in the early

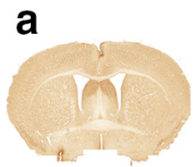

Wild-type

b

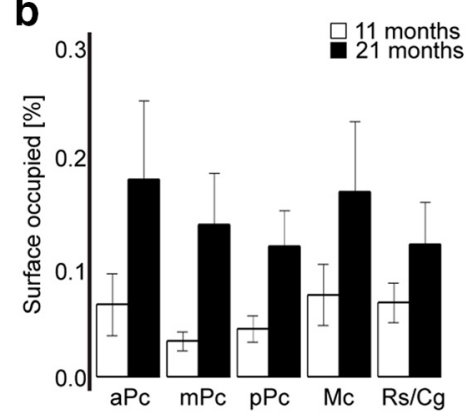

2 months

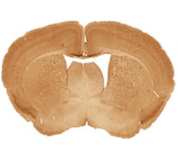

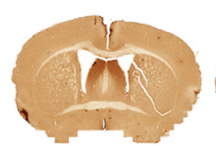

5 months

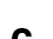

C

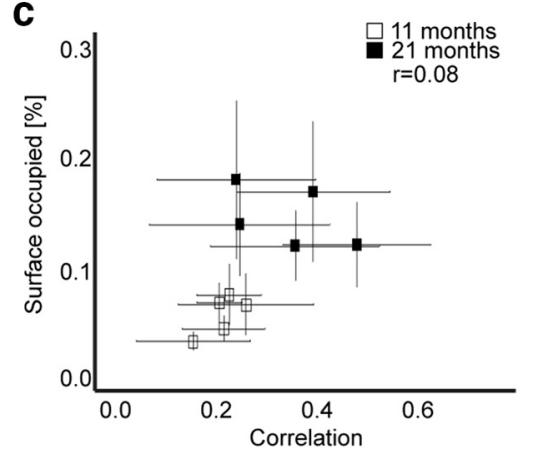

Figure 7. Immunohistological detection of $A \beta$ peptides $\operatorname{Arc} A \beta$ transgenic mice at 2, 5, 11, and 21 months, and wild-type control reveal sparse amyloid plaques at 5 months with increasing plaque load at 11 and 21 months $(\boldsymbol{a})$. ROl analysis of the cortical areas was used to estimate the surface occupied by the amyloid plaques at 11 and 21 months $(\boldsymbol{b})$. Correlation analysis indicate no apparent link between amyloid plaque surface occupancy and functional connectivity for the corresponding regions $(\boldsymbol{c} ; r=0.08)$. Error bars represent \pm 1 SD. Scale bar, $1 \mathrm{~mm}$. phase of life, whereas it appeared increased in young APP/PS1 compared with wild-type, further, we could not correlate functional changes to amyloid plaque burden. Yet, given the large phenotypic variations between mouse models of $\mathrm{AD}$ (Balducci and Forloni, 2011), different FC patterns and dynamics are to be expected. In fact, a comparative study of FC patterns between 


\section{a Reproducibility}

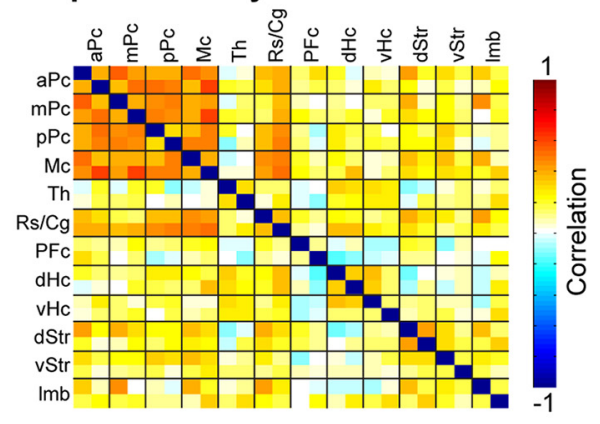

b Test-retest mPc

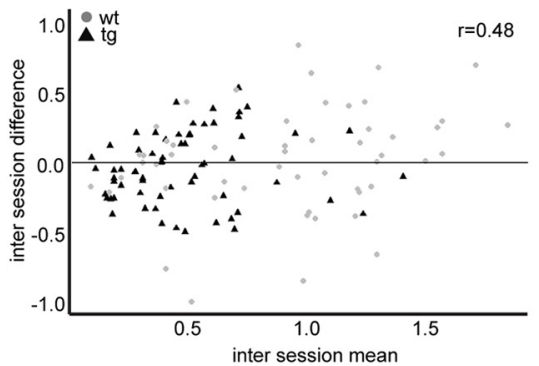

C tSNR

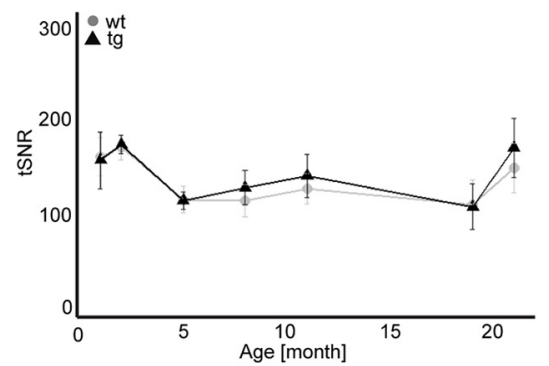

Figure 8. Reproducibility of functional connectivity assessment was evaluated by comparing the coefficients of correlation of the results in the two rs-fMRI sessions recorded at 1 week intervals for every animal at a given age $(\boldsymbol{a})$. Reproducibility ranged between $r=0.4$ and $r=0.58$ between the cortical regions pairwise correlation, and -0.01 to 0.2 in the subcortical interactions. Intersession mean and difference is shown for the medial parietal cortex pairwise correlation, illustrating the reproducibility of the measure in cortical regions ( $\boldsymbol{b}$ ). The tSNR is shown per age group and genotype, and indicates a peak at 2 and 21 months, with tSNR values ranging between 105 and 169 (c). Error bars represent 1 SD.

different transgenic lines may highlight salient features necessary and sufficient to alter neuronal networks.

A potential confound in the study of FC in rodents is interference by anesthesia. Although it has been reported that rats could be trained to undergo fMRI sessions in awake state (Liang et al., 2011), FC studies have been reported as being difficult to apply in mice due to difficulties in acclimating the animals (Jonckers et al., 2013). However, FC pattern in isoflurane anesthetized mice were shown to be strikingly similar to those recorded in the awake state (Jonckers et al., 2013). All anesthetics interact with neurotransmitter systems, which might be affected in a differential way in different mouse lines. For example the GABAergic system, being a target of several anesthetics including isoflurane (Kotani and Akaike, 2013), appears to be affected by amyloid toxicity already in early life of transgenic animals of cerebral amyloidosis (Krantic et al., 2012). Hence, isoflurane anesthesia may exacerbate the effects of amyloidosis in fMRI studies in these animals. We nevertheless decided to use this anesthetic as it apparently preserves cortical connectivity to a large extent when compare with the awake state (Jonckers et al., 2013).

Alzheimer's disease often involves amyloid deposition around the vasculature (Weller et al., 1998), which inherently affects the neurovascular coupling and potentially masks FC measured on the basis of hemodynamic readouts, such as BOLD fMRI (Nicolakakis and Hamel, 2011) and intrinsic optical imaging (Bero et al., 2012). A number of structural and functional consequences of vasculopathy have been reported in murine models of amyloidosis, such as reduced cortical blood flow already early in life (Hébert et al., 2013), as well as damaged capillary systems (Meyer et al., 2008). The ArcA $\beta$ model displays vascular pathology at a young age (Merlini et al., 2011) leading in old animals to cerebral microbleeds (Klohs et al., 2011), impaired vascular reactivity (Princz-Kranz et al., 2010), and vascular remodeling (Klohs et al., 2012). As a result, it remains unclear whether the FC alterations in these mice are of neural or vascular origin, or both. A potential contribution of altered neurovascular coupling should also be considered when interpreting functional impairments in $\mathrm{AD}$ patients as derived from fMRI studies, as a significant fraction of these patients is affected by severe vasculopathy (Castellani et al., 2004).

Interestingly, the impaired development of FC in transgenic animals during the 1-5 month period is also reflected by an altered FA evolution in specific white matter structures, which may, suggest a neuronal rather than vascular basis for the func- tional changes. FA evolution during the first months of life has been related to maturation of myelination in rats (Mengler et al., 2014). Diffusion tensor imaging in the APP/PS1 model revealed a FA difference map overlapping with our results, including increased FA in the minor forceps (Shu et al., 2013). The animal data differ from patterns of FA changes in patients with $\mathrm{AD}$, where regions marked by reduced FA include the temporal lobes, hippocampus, posterior cingulum and occipital lobe (Stebbins and Murphy, 2009).

The dynamics of alteration, both spatial and temporal, differ from patterns observed in AD patients, which is marked with early altered FC in the default mode network and aggravated FC in the transition from mild cognitive impairments to AD (Greicius et al., 2004; Rombouts et al., 2005; Sorg et al., 2007; Sheline et al., 2010a,b). The discrepancy in regional FC impairments between mice and human might be related to a link between neuronal activity and $\mathrm{A} \beta$ release affecting $\mathrm{FC}$ strength and amyloid deposition in later life (Bero et al., 2011, 2012). Although, in humans, the DMN is the metabolically most active network in the brain at rest (Raichle et al., 2001), the somatosensory cortex appears as metabolically active as the cingulate in mice (Nicholson et al., 2010). In fact, FC involving somatosensory ROIs shows the highest correlation coefficients in our study, supporting the hypothesis linking high brain activity to $\mathrm{A} \beta$ pathology.

Another discrepancy with regards to human pathological progression related to the marginal decline in FC in $\operatorname{ArcA} \beta$ mice between 5 and 21 months of age despite massively increasing amyloid plaque load, consistent with the dissociation between amyloid load and connectivity (Adriaanse et al., 2014), but inconsistent with the observed aggravation of FC associated with transition from preclinical to clinical AD (Rombouts et al., 2005). The changes observed suggest an impaired functional and structural network maturation in $\operatorname{ArcA} \beta$, however the biological mechanisms underlying the phenomenon remain elusive due to the many effects attributed to elevated $\mathrm{A} \beta$ peptide concentration. Mechanisms might involve altered LTP (Knobloch et al., 2007a), axon misguiding (Cao et al., 2012), and/or alterations in cerebral calcium homeostasis (Kuchibhotla et al., 2008).

In conclusion, we have shown using rs-fMRI that in the $\operatorname{ArcA} \beta$ transgenic mouse model of cerebral amyloidosis that the development of FC during the first months of life is impaired as compared with age-matched wild-type mice, with effects being most pronounced for FC involving ROIs in the somatosensory and motor cortex. Changes in FC are among the earliest detect- 
able feature in cerebral amyloidosis, both in human and animal models; however, the diagnostic value of this readout is hampered by poor reproducibility at the individual level. This remains a caveat of the method, which requires large groups of animals/patients or large effects to properly power future studies. Effects on FC are paralleled by structural changes as derived from analysis of the FA of water diffusion, and occur in the early amyloid plaque buildup stage. Several factors may explain the observed alteration, including defective maturation of both FC and FA, reduced synaptic activity, or impaired cerebrovascular system. The variety of transgenic models of cerebral amyloidosis offers an experimental platform to elucidate features necessary and sufficient to alter neuronal networks, to study the effects of disease modifying agents, and to bridge mechanistic information at a molecular and cellular level to functional/physiological readouts obtained at the system level, that can be ultimately translated to neuroimaging studies in humans.

\section{References}

Adriaanse SM, Sanz-Arigita EJ, Binnewijzend MA, Ossenkoppele R, Tolboom N, van Assema DM, Wink AM, Boellaard R, Yaqub M, Windhorst AD, van der Flier WM, Scheltens P, Lammertsma AA, Rombouts SA, Barkhof F, van Berckel BN (2014) Amyloid and its association with default network integrity in Alzheimer's disease. Hum Brain Mapp 35:779-791. CrossRef Medline

Balducci C, Forloni G (2011) APP transgenic mice: their use and limitations. Neuromolecular Med 13:117-137. CrossRef Medline

Benjamini Y, Hochberg Y (1995) Controlling the false discovery rate: a practical and powerful approach to multiple testing. J R Stat Soc Ser B 57:289-300.

Bero AW, Yan P, Roh JH, Cirrito JR, Stewart FR, Raichle ME, Lee JM, Holtzman DM (2011) Neuronal activity regulates the regional vulnerability to amyloid-beta deposition. Nat Neurosci 14:750-756. CrossRef Medline

Bero AW, Bauer AQ, Stewart FR, White BR, Cirrito JR, Raichle ME, Culver JP, Holtzman DM (2012) Bidirectional relationship between functional connectivity and amyloid-beta deposition in mouse brain. J Neurosci 32:4334-4340. CrossRef Medline

Buckner RL, Snyder AZ, Shannon BJ, LaRossa G, Sachs R, Fotenos AF, Sheline YI, Klunk WE, Mathis CA, Morris JC, Mintun MA (2005) Molecular, structural, and functional characterization of Alzheimer's disease: evidence for a relationship between default activity, amyloid, and memory. J Neurosci 25:7709-7717. CrossRef Medline

Canuet L, Tellado I, Couceiro V, Fraile C, Fernandez-Novoa L, Ishii R, Takeda M, Cacabelos R (2012) Resting-state network disruption and APOE genotype in Alzheimer's disease: a lagged functional connectivity study. PLoS One 7:e46289. CrossRef Medline

Cao L, Schrank BR, Rodriguez S, Benz EG, Moulia TW, Rickenbacher GT, Gomez AC, Levites Y, Edwards SR, Golde TE, Hyman BT, Barnea G, Albers MW (2012) A $\beta$ alters the connectivity of olfactory neurons in the absence of amyloid plaques in vivo. Nat Commun 3:1009. CrossRef Medline

Castellani RJ, Smith MA, Perry G, Friedland RP (2004) Cerebral amyloid angiopathy: major contributor or decorative response to Alzheimer's disease pathogenesis. Neurobiol Aging 25:599-602; discussion 603-604. CrossRef Medline

Damoiseaux JS, Rombouts SA, Barkhof F, Scheltens P, Stam CJ, Smith SM, Beckmann CF (2006) Consistent resting-state networks across healthy subjects. Proc Natl Acad Sci U S A 103:13848-13853. CrossRef Medline

Glover GH, Li TQ, Ress D (2000) Image-based method for retrospective correction of physiological motion effects in fMRI: RETROICOR. Magn Reson Med 44:162-167. CrossRef Medline

Gordon MN, Holcomb LA, Jantzen PT, DiCarlo G, Wilcock D, Boyett KW, Connor K, Melachrino J, O'Callaghan JP, Morgan D (2002) Time course of the development of Alzheimer-like pathology in the doubly transgenic PS1+APP mouse. Exp Neurol 173:183-195. CrossRef Medline

Greicius MD, Krasnow B, Reiss AL, Menon V (2003) Functional connectivity in the resting brain: a network analysis of the default mode hypothesis. Proc Natl Acad Sci U S A 100:253-258. CrossRef Medline

Greicius MD, Srivastava G, Reiss AL, Menon V (2004) Default-mode network activity distinguishes Alzheimer's disease from healthy aging: evi- dence from functional MRI. Proc Natl Acad Sci U S A 101:4637-4642. CrossRef Medline

Hébert F, Grand'maison M, Ho MK, Lerch JP, Hamel E, Bedell BJ (2013) Cortical atrophy and hypoperfusion in a transgenic mouse model of Alzheimer's disease. Neurobiol Aging 34:1644-1652. CrossRef Medline

Hedden T, Van Dijk KR, Becker JA, Mehta A, Sperling RA, Johnson KA, Buckner RL (2009) Disruption of functional connectivity in clinically normal older adults harboring amyloid burden. J Neurosci 29:1268612694. CrossRef Medline

Iwatsubo T, Odaka A, Suzuki N, Mizusawa H, Nukina N, Ihara Y (1994) Visualization of A beta 42(43) and A beta 40 in senile plaques with endspecific A beta monoclonals: evidence that an initially deposited species is A beta 42(43). Neuron 13:45-53. CrossRef Medline

Johnson KA, Fox NC, Sperling RA, Klunk WE (2012) Brain imaging in Alzheimer disease. Cold Spring Harb Perspect Med 2:a006213. CrossRef Medline

Jonckers E, Delgado YPR, Shah D, Guglielmetti C, Verhoye M, Van der Linden A (2013) Different anesthesia regimes modulate the functional connectivity outcome in mice. Magn Reson Med. Advance online publication. Retrieved April 9, 2014. doi:10.1002/mrm.24990. CrossRef Medline

Klohs J, Deistung A, Schweser F, Grandjean J, Dominietto M, Waschkies C, Nitsch RM, Knuesel I, Reichenbach JR, Rudin M (2011) Detection of cerebral microbleeds with quantitative susceptibility mapping in the Arc $\mathrm{A} \beta$ mouse model of cerebral amyloidosis. J Cereb Blood Flow Metab 31:2282-2292. CrossRef Medline

Klohs J, Baltes C, Princz-Kranz F, Ratering D, Nitsch RM, Knuesel I, Rudin M (2012) Contrast-enhanced magnetic resonance microangiography reveals remodeling of the cerebral microvasculature in transgenic $\operatorname{ArcA} \beta$ mice. J Neurosci 32:1705-1713. CrossRef Medline

Knobloch M, Farinelli M, Konietzko U, Nitsch RM, Mansuy IM (2007a) A $\beta$ oligomer-mediated long-term potentiation impairment involves protein phosphatase 1-dependent mechanisms. J Neurosci 27:7648-7653. CrossRef Medline

Knobloch M, Konietzko U, Krebs DC, Nitsch RM (2007b) Intracellular A $\beta$ and cognitive deficits precede beta-amyloid deposition in transgenic $\operatorname{arcA} \beta$ mice. Neurobiol Aging 28:1297-1306. CrossRef Medline

Kotani N, Akaike N (2013) The effects of volatile anesthetics on synaptic and extrasynaptic GABA-induced neurotransmission. Brain Res Bull 93: 69-79. CrossRef Medline

Krantic S, Isorce N, Mechawar N, Davoli MA, Vignault E, Albuquerque M, Chabot JG, Moyse E, Chauvin JP, Aubert I, McLaurin J, Quirion R (2012) Hippocampal GABAergic neurons are susceptible to amyloid- $\beta$ toxicity in vitro and are decreased in number in the Alzheimer's disease TgCRND8 mouse model. J Alzheimers Dis 29:293-308. CrossRef Medline Kuchibhotla KV, Goldman ST, Lattarulo CR, Wu HY, Hyman BT, Bacskai BJ (2008) $\mathrm{A} \beta$ plaques lead to aberrant regulation of calcium homeostasis in vivo resulting in structural and functional disruption of neuronal networks. Neuron 59:214-225. CrossRef Medline

Liang Z, King J, Zhang N (2011) Uncovering intrinsic connectional architecture of functional networks in awake rat brain. J Neurosci 31:37763783. CrossRef Medline

Mengler L, Khmelinskii A, Diedenhofen M, Po C, Staring M, Lelieveldt BP, Hoehn M (2014) Brain maturation of the adolescent rat cortex and striatum: changes in volume and myelination. Neuroimage 84:35-44. CrossRef Medline

Merlini M, Meyer EP, Ulmann-Schuler A, Nitsch RM (2011) Vascular betaamyloid and early astrocyte alterations impair cerebrovascular function and cerebral metabolism in transgenic $\operatorname{arcA} \beta$ mice. Acta Neuropathol 122:293-311. CrossRef Medline

Meyer EP, Ulmann-Schuler A, Staufenbiel M, Krucker T (2008) Altered morphology and 3D architecture of brain vasculature in a mouse model for Alzheimer's disease. Proc Natl Acad Sci U S A 105:3587-3592. CrossRef Medline

Mucke L, Selkoe DJ (2012) Neurotoxicity of amyloid $\beta$-protein: synaptic and network dysfunction. Cold Spring Harb Perspect Med 2:a006338. CrossRef Medline

Nicholson RM, Kusne Y, Nowak LA, LaFerla FM, Reiman EM, Valla J (2010) Regional cerebral glucose uptake in the 3xTG model of Alzheimer's disease highlights common regional vulnerability across $\mathrm{AD}$ mouse models. Brain Res 1347:179-185. CrossRef Medline 
Nicolakakis N, Hamel E (2011) Neurovascular function in Alzheimer's disease patients and experimental models. J Cereb Blood Flow Metab 31: 1354-1370. CrossRef Medline

Princz-Kranz FL, Mueggler T, Knobloch M, Nitsch RM, Rudin M (2010) Vascular response to acetazolamide decreases as a function of age in the $\operatorname{arcA} \beta$ mouse model of cerebral amyloidosis. Neurobiol Dis 40:284-292. CrossRef Medline

Raichle ME, MacLeod AM, Snyder AZ, Powers WJ, Gusnard DA, Shulman GL (2001) A default mode of brain function. Proc Natl Acad Sci U S A 98:676-682. CrossRef Medline

Rombouts SA, Barkhof F, Goekoop R, Stam CJ, Scheltens P (2005) Altered resting state networks in mild cognitive impairment and mild Alzheimer's disease: an fMRI study. Hum Brain Mapp 26:231-239. CrossRef Medline

Sheline YI, Morris JC, Snyder AZ, Price JL, Yan Z, D’Angelo G, Liu C, Dixit S, Benzinger T, Fagan A, Goate A, Mintun MA (2010a) APOE4 allele disrupts resting state fMRI connectivity in the absence of amyloid plaques or decreased CSF A $\beta 42$. J Neurosci 30:17035-17040. CrossRef Medline

Sheline YI, Raichle ME, Snyder AZ, Morris JC, Head D, Wang S, Mintun MA (2010b) Amyloid plaques disrupt resting state default mode network connectivity in cognitively normal elderly. Biol Psychiatry 67:584-587. CrossRef Medline

Shu X, Qin YY, Zhang S, Jiang JJ, Zhang Y, Zhao LY, Shan D, Zhu WZ (2013) Voxel-based diffusion tensor imaging of an APP/PS1 mouse model of Alzheimer's disease. Mol Neurobiol 48:78-83. CrossRef Medline

Sorg C, Riedl V, Mühlau M, Calhoun VD, Eichele T, Läer L, Drzezga A, Förstl H, Kurz A, Zimmer C, Wohlschläger AM (2007) Selective changes of resting-state networks in individuals at risk for Alzheimer's disease. Proc Natl Acad Sci U S A 104:18760-18765. CrossRef Medline

Sperling RA, Laviolette PS, O'Keefe K, O’Brien J, Rentz DM, Pihlajamaki M, Marshall G, Hyman BT, Selkoe DJ, Hedden T, Buckner RL, Becker JA, Johnson KA (2009) Amyloid deposition is associated with impaired default network function in older persons without dementia. Neuron 63 : 178-188. CrossRef Medline

Stebbins GT, Murphy CM (2009) Diffusion tensor imaging in Alzheimer's disease and mild cognitive impairment. Behav Neurol 21:39-49. CrossRef Medline

Weller RO, Massey A, Newman TA, Hutchings M, Kuo YM, Roher AE (1998) Cerebral amyloid angiopathy: amyloid beta accumulates in putative interstitial fluid drainage pathways in Alzheimer's disease. Am J Pathol 153:725-733. CrossRef Medline 